\title{
Diagnostic tests for Helicobacter pylori: Comparison and influence of non-steroidal anti-inflammatory drugs
}

\author{
A S Taha, P Boothman, I Nakshabendi, J Reid, C Morran, C G Gemmell, F D Lee, \\ R D Sturrock, R I Russell
}

\begin{abstract}
Aims: To evaluate the efficacy of culture, histology, CLO-test, Helico-G and Pyloriset tests in diagnosing Helicobacter pylori in the presence or absence of nonsteroidal anti-inflammatory drugs (NSAIDs).

Methods: Of 134 patients studied, 75 had taken NSAIDs. At endoscopy, biopsy specimens were taken for culture, histology, and CLO-test. Blood was also taken for enzyme linked immunosorbent assay (ELISA) (Helico-G) and latex agglutination (Pyloriset) tests.

Results: The sensitivity, specificity, and predictive values of histology and CLOtest, compared with culture, ranged from $\mathbf{9 0 \%}$ to $\mathbf{9 7 \%}$, regardless of NSAID intake. In the 59 patients not taking NSAIDs Helico-G had a sensitivity of $75 \%$ $(p<0.05)$ and a specificity of $61 \%$; Pyloriset's sensitivity and specificity were, respectively, $63 \%(p<0.05)$ and $67 \%$. In the 75 patients taking NSAIDs the sensitivity of Helico-G was $81 \%$ and its specificity $45 \%(p<0.05) ;$ Pyloriset had a sensitivity of $61 \%(p<0.05)$ and a specificity of $50 \%$ (p $<0.05)$.

Conclusion: These findings suggest that $H$ pylori is more reliably diagnosed by culture, histology, and CLO-test than by the serological tests used in this study, especially in patients treated with NSAIDs.
\end{abstract}

The increasing realisation of the importance of Helicobacter pylori in the development, treatment, and recurrence of peptic ulceration ${ }^{1-5}$ has made the identification of these organisms an essential part of the investigation and management of peptic ulcer disease. Several tests have been proposed, including culture, histology, urease enzyme activity, and serological tests. ${ }^{6-12}$ The value of such methods in general and the serological tests in particular has not been fully established. Their application to patients treated with non-steroidal antiinflammatory drugs (NSAIDs), who are at a particular risk of developing peptic damage, has not been adequately investigated.

\section{Methods}

Patients over the age of 18 years were recruited from the gastroenterology and rheumatology clinics. NSAIDs had to have been taken for a minimum of four weeks before endoscopy. Patients were excluded if they had a history of gastric surgery or if they had received antibiotics or drugs intended to heal ulcers within two weeks of endoscopy.

Informed consent was obtained and endoscopy carried out, using 3-6 mg midazolam intravenously for sedation, within three hours of taking $10 \mathrm{ml}$ of venous blood for serology tests. Biopsy specimens were taken from healthy looking mucosa in the gastric antrum, at least $2 \mathrm{~cm}$ away from the edge of the ulcer, in patients with ulcers, for culture (one specimen), histology (two specimens), and CLOtest (one specimen). In patients with ulcers biopsy specimens were also taken from the ulcer edge and base to exclude malignancy which, if found, precluded patients from the final analysis.

$H$ pylori was detected by culture and histology, as previously described. ${ }^{13}$ Gastritis was classified according to the Whitehead system, modified to cover chemical and lymphocytic gastritis. ${ }^{14-17}$

Urease activity was tested for by inserting one antral biopsy specimen, immediately after it had been obtained, into the gel pellet of the CLO-test slide (Delta-West Ltd, Bentley, Western Australia). The slides were reviewed for the positive red colouration at three and 24 hours.

Serum IgG $H$ pylori antibodies were measured using a quantitive commercial IgG ELISA (Helico-G) according to the manufacturer's instructions (Porton Cambridge, Maidenhead, England). In summary, a standard curve was prepared and $100 \mu \mathrm{l}$ serum aliquotes were dispensed into microwell strips precoated with $H$ pylori cell membrane-derived antigen. The microwells were incubated at $37^{\circ} \mathrm{C}$ for one hour, washed in buffer, and $100 \mu \mathrm{l}$ antibody conjugate added, to be incubated again for 30 minutes and washed as above. Substrate chromogen $(100 \mu 1$ of tetramethylbenzidine) was added, shaken for 10 minutes, and the reaction was then stopped using $50 \mu \mathrm{l}$ of $2 \mathrm{M}$ sulphuric acid. Each microwell was then read at an absorbance of $450 \mathrm{~nm}$ in an ELISA reader (Labsystems, Uxbridge, England). An antibody titre of 10 units or more was considered indicative of infection with $H$ pylori.

To test for IgG $H$ pylori antibodies by latex agglutination, Pyloriset (Orion Diagnostica. Finland) was used. The test uses latex particles coated with acid extracted antigen of $H$ pylori. A drop $(40 \mu \mathrm{l})$ of patient's serum, already 
Table 1 Patients' demographic details

\begin{tabular}{llll}
\hline & $\begin{array}{l}\text { Patients receiving } \\
\text { NSAIDs }\end{array}$ & $\begin{array}{l}\text { Patients not } \\
\text { receiving NSAIDs }\end{array}$ & Total \\
\hline Number & 75 & 59 & 134 \\
Males & 22 & 18 & 40 \\
Females & 53 & 41 & 94 \\
$\begin{array}{l}\text { Age (years) } \\
\text { median (interquartile ranges) }\end{array}$ & $56(44-66)$ & $47(36-65)$ & 53 \\
$\quad$ Smokers & 27 & 21 & $(39-65)$ \\
$\begin{array}{l}\text { Drinkers } \\
\text { Abdominal symptoms }\end{array}$ & 34 & 33 & 68 \\
\hline
\end{tabular}

Table 2 Types of NSAIDs and second line drugs used

\begin{tabular}{lr}
\hline NSAIDs: & 17 \\
Indomethacin & 9 \\
Naproxen & 8 \\
Fenbufen & 7 \\
Diclofenac & 6 \\
Ketoprofen & 6 \\
Ibuprofen & 5 \\
Piroxicam & 5 \\
Flurbiprofen & 5 \\
Nabumetone & 6 \\
Others & \\
Second line drugs: & 15 \\
Sulphasalazine & 15 \\
Sodium aurothiomalate & 7 \\
Hydroxychloroquine & 5 \\
Penicillamine & 5 \\
\hline
\end{tabular}

diluted 1 in 2 in phosphate-saline buffer, was placed in the centre of the test slide, and one drop of latex reagent was added to be mixed with the serum. The test slide was then gently rotated for three minutes and observed for evidence of agglutination. A positive result was taken as white granules on a black background. In each series of tests positive and negative sera were used as controls.

Statistical analyses included $\chi^{2}$ test with correction for multiple comparisons, analysis of variance, and McNemar's test ${ }^{18}$ where appropriate. Patients underwent endoscopic examination at random, and all specimens carried code numbers to facilitate randomisation.

\section{Results}

A total of 134 patients entered the final analysis: 75 had taken NSAIDs (table 1). Patients in both groups were comparable in their ages, smoking and drinking habits, and the prevalence of abdominal complaints. The detail of NSAIDs and second line drugs used by patients with rheumatoid arthritis (NSAID group) are presented in table 2 . The NSAIDs taken by most patients in this group are known for their potent anti-inflammatory activity and relatively strong ulcerogenic potential. The median duration of their intake was two years.

Patients not treated with NSAIDs, who are positive for $H$ pylori according to various tests, are shown in table 3 . They are subgrouped according to the presence or absence of symptoms, and endoscopic and histological findings. Similar numbers of $H$ pylori positive patients were identified by culture, histology, and CLO-test in various subgroups. Although such numbers were greater but not significantly different from those identified by the serological tests, the latter included more false positive cases which in turn resulted in lower specificity (table 4 ).

$H$ pylori positive patients in the NSAID group, classified according to their symptoms and endoscopic findings, are shown in table 5. The serological tests, Helico-G in particular, diagnosed greater numbers of $H$ pylori positive patients receiving NSAIDs, but the importance of this finding is limited by the low specificity of such tests (see below). It is also worth noting that patients treated with NSAIDs had a total of 30 cases of ulcers or erosions $(30 / 75,40 \%)$, and only 18 of these $(18 / 30,60 \%)$ were associated with abdominal complaints.

The histological abnormalities in patients receiving NSAIDs and the corresponding numbers of $H$ pylori positive cases are shown in table 6 . The major abnormality was that of chronic superficial gastritis, followed by chemical gastritis. $H$ pylori was identified in more than $60 \%$ of cases of chronic superficial gastritis by all tests used, with the greatest proportion ( $83 \%$ ) diagnosed by Helico-G test. Six of $11(54 \%)$ cases of chemical gastritis were associated with peptic damage, compared with 18 of $36(50 \%)$ with $H$ pylori, and six of 29 $(21 \% ; p<0.05)$ in patients without chemical gastritis or $H$ pylori.

The sensitivity, specificity, and predictive values of various tests, compared with culture, are summarised in table 4. Histology and CLO-test had the highest sensitivity, specificity, and predictive values, regardless of NSAID intake. Helico-G and Pyloriset tests had the lowest specificity and negative predictive values in patients treated with NSAIDs. Compared with Pyloriset, Helico-G had higher sensitivity and positive values but lower specificity and negative predictive values, in the presence or absence of NSAIDs.

Using culture, histology, and CLO-test, the prevalence of $H$ pylori in the NSAID group was $43-48 \%$ compared with $64-69 \%$ in patients not treated with NSAIDs $(p<0.01)$; no significant differences were detected using Helico-G or Pyloriset tests. $H$ pylori IgG titres measured by Helico-G in patients taking NSAIDs were also comparable with those in patients not receiving such drugs. Of 15 patients treated with gold and NSAIDs, five were positive for $H$ pylori by culture, and this did not alter the interpretation of the above mentioned findings. The presence or absence of rheumatoid factor did not seem to influence the sensitivity or specificity of the serological tests used in this study.

Table $3 H$ pylori positivity in 59 patients not treated with NSAIDs (No (\%)

\begin{tabular}{|c|c|c|c|c|c|}
\hline \multirow[b]{2}{*}{ Total number of patients } & \multicolumn{5}{|c|}{ Patients positive for $H$ pylori } \\
\hline & Culture & Histology & CLO-Test & Helico-G & Pyloriset \\
\hline Symptomatic patients $(n=39)$ & $32(82)$ & $31(80)$ & $31(80)$ & $24(62)$ & $24(62)$ \\
\hline $\begin{array}{l}\text { Endoscopic findings: } \\
\text { Normal }(n=53) \\
\text { Ulcers }(n=6)\end{array}$ & $\begin{array}{c}36 \\
5\end{array}$ & $\begin{array}{c}35 \\
5\end{array}$ & $\begin{array}{c}33(62) \\
6\end{array}$ & $\begin{array}{c}34 \\
3\end{array}(64)$ & $\begin{array}{c}27 \\
4\end{array}$ \\
\hline $\begin{array}{l}\text { Histological findings: } \\
\text { Normal }(n=14) \\
\text { Chronic superficial gastritis }(n=40) \\
\text { Chronic atrophic gastritis }(n=3)\end{array}$ & $\begin{array}{r}5(36) \\
33(83) \\
3\end{array}$ & $\begin{array}{r}4(29) \\
33(83) \\
3\end{array}$ & $\begin{array}{r}5(36) \\
32(80) \\
2\end{array}$ & $\begin{array}{r}4(29) \\
31(78) \\
2\end{array}$ & $\begin{array}{r}3(21) \\
27(68) \\
1\end{array}$ \\
\hline
\end{tabular}


Table 4 Sensitivity, specificity, positive (PPV) and negative (NPV) predictive values of tests used, with culture taken as a standard

\begin{tabular}{lllll}
\hline & Histology & CLO-Test & Helico-G & Pyloriset \\
\hline Patients not taking NSAIDs: & & & & \\
Sensitivity & $95 \%$ & $93 \%$ & $75 \%^{\star}$ & $63 \%^{\star}$ \\
Specificity & $94 \%$ & $94 \%$ & $61 \%$ & $67 \%^{\star}$ \\
PPV & $95 \%$ & $93 \%$ & $76 \%$ & $61 \%$ \\
NPV & $95 \%$ & $95 \%$ & $61 \%$ & $67 \%$ \\
Patients taking NSAIDs: & & & & \\
Sensitivity & $97 \%$ & $90 \%$ & $81 \%$ & $61 \%^{\star}$ \\
Specificity & $90 \%$ & $97 \%$ & $45 \%^{\star}$ & $50 \%^{\star}$ \\
PPV & $97 \%$ & $90 \%$ & $83 \%$ & $64 \%$ \\
NPV & $90 \%$ & $97 \%$ & $44 \%$ & $49 \%$
\end{tabular}

Significant differences after correction for multiple comparison: ${ }^{\star}: p<0.05$, McNemar's test, compared with histology. that the natural history of peptic ulceration can be altered by such agents. Firstly, although more than $30 \%$ of patients taking NSAIDs might develop peptic damage ${ }^{2223}$ many such lesions can be completely asymptomatic, as shown by this study and others. ${ }^{24}$ Secondly, NSAIDs seem to reduce the prevalence of $H$ pylori infection, as suggested by data produced at our units and elsewhere. ${ }^{172527}$ Such features of NSAID induced peptic damage might limit the value of finding a positive IgG related serological test in predicting ulcer disease. ${ }^{10}$ This needs to be taken into consideration especially when serological testing is not supplemented with endoscopic, culture, or histological assessments. ${ }^{28}$

The reason for the low prevalence of $H$ pylori in the presence of NSAIDs remains a matter of speculation. It could be due to direct toxic action against the organisms, or it could be indirectly related to the effect of NSAIDs on the gastric mucosa. Aspirin and indomethacin increased basal ${ }^{29}$ and maximally stimulated gastric acid secretion. ${ }^{30-31}$ Aspirin $^{32}$ and indomethacin ${ }^{33}$ also inhibited mucus secretion. This rise in gastric acid and the interference with the mucus layer by NSAIDs might in turn make it difficult for $\mathrm{H}$ pylori organisms to survive under such unfavourable conditions.

The median duration of NSAID intake in this study was two years. Assuming that some patients became negative for $H$ pylori during this time, the behaviour of their serum antibody titres could not be predicted as the precise time of their conversion was not known. Recent studies have suggested that such titres might fall ${ }^{34}$ or remain unchanged. ${ }^{20}$

In this study chemical gastritis was only found in patients taking NSAIDs. $H$ pylori IgG antibodies were detected in five patients with chemical gastritis $(5 / 11,45 \%)$ while the presence of $H$ pylori organisms was confirmed in only one of these cases. This discrepancy between the serological and biopsy tests might again support the suggestion that the positive serology reflects previous infection with $H$

Table 5 H pylori positivity in patients taking NSAIDs with symptoms or endoscopic abnormalities (no/(\%))

\begin{tabular}{|c|c|c|c|c|c|}
\hline \multirow[b]{2}{*}{ Total number of patients } & \multicolumn{5}{|c|}{ Patients positive for $H$ pylori } \\
\hline & Culture & Histology & CLO-Test & Helico-G & Pyloriset \\
\hline Symptomatic patients $(n=36)$ & $17(47)$ & $19(53)$ & $16(44)$ & $24(67)$ & $19(53)$ \\
\hline $\begin{array}{l}\text { Endoscopic findings: } \\
\text { Normal }(n=45) \\
\text { Erosions }(n=8) \\
\text { Gastric ulcers }(n=14) \\
\text { Duodenal ulcers }(n=8) \\
\text { Symptomatic endoscopic lesions }(n=18)\end{array}$ & $\begin{array}{r}19(42) \\
3(38) \\
9(64) \\
6(75) \\
9(50)\end{array}$ & $\begin{array}{r}23(51) \\
3(38) \\
9(64) \\
6(75) \\
10(56)\end{array}$ & $\begin{array}{r}19(42) \\
3(38) \\
7(50) \\
5(63) \\
8(44)\end{array}$ & $\begin{array}{r}29(64) \\
5(63) \\
12(86) \\
5(63) \\
12(67)\end{array}$ & $\begin{array}{r}22(49) \\
4(50) \\
12(86) \\
3(38) \\
11(61)\end{array}$ \\
\hline
\end{tabular}

Table $6 H$ pylori positivity in patients taking NSAIDs with histological abnormalities (no/(\%))

\begin{tabular}{llllll}
\hline & \multicolumn{4}{l}{ Patients positive for H pylori } & \\
\cline { 2 - 6 } Total number of patients & Culture & Histology & CLO-Test & Helico-G & Pyloriset \\
\hline Chronic superficial gastritis $(\mathrm{n}=46)$ & $30(65)$ & $34(74)$ & $29(63)$ & $38(83)$ & $30(65)$ \\
Lymphocytic gastritis $(\mathrm{n}=4)$ & 4 & 4 & 4 & 3 & 5 \\
Chemical gastritis $(\mathrm{n}=11)$ & 1 & 1 & 1 & 5 & 2 \\
Normal histology $(\mathrm{n}=14)$ & 1 & 1 & 0 & 2 & 2 \\
\hline
\end{tabular}


pylori which could have been eradicated, or at least altered, by NSAID intake. ${ }^{172527}$

Peptic ulcers or erosions associated with NSAID intake were found in $54 \%$ of patients with chemical gastritis and $50 \%$ of those with $H$ pylori, compared with only $21 \%$ of other patients in the NSAID group. This agrees with our recent data suggesting that the prevalence of NSAID induced peptic damage seems to be increased by the presence of chemical gastritis or $H$ pylori. ${ }^{17}$

In conclusion, culture, histology, and CLOtest have comparable sensitivity and specificity which do not seem to be influenced by NSAID intake. However, IgG antibody serology tests (Helico-G and Pyloriset) seem to be less useful than the above tests involving the use of gastric biopsy specimens. Such differences are further emphasised in patients treated with NSAIDs. The use of improved serological tests should still be considered because of their noninvasive nature, low cost, time and labour saving potential.

We thank Porton Cambridge, Maidenhead, England and Orion Diagnostica, Finland, for donating some of the Helico-G and Pyloriset kits. We also thank Miss Stephanie McLaughlin for her help in the statistical analyses, Miss Jacqueline Kennedy for her secretarial assistance, and Merck Sharp and Dohme for their financial support.

1 Warren J, Marshall B. Unidentified curved bacilli on gastric epithelium in active chronic gastritis. Lancet 1983; i: $1273-5$.

2 Price A, Levi J, Dolby J, et al. Campylobacter pyloridis in peptic ulcer disease: microbiology, pathology and scanning microscopy. Gut 1985;26:1183-8.

3 Coghan J, Humphries H, Dooley C, et al. Campylobacter pylori and recurrence of duodenal ulcers - a 12 month pylori and recurrence of duodenal

4 Marshall B, Warren J, Blincow E, et al. Prospective doubleblind trial of duodenal ulcer relapse after eradication of blind trial of duodenal ulcer relapse after eradica
Campylobacter pylori. Lancet 1988 ;ii:1437-42.

5 Rauws EA, Tytgat GN. Cure of duodenal ulcer associated with eradication of Helicobacter pylori. Lancet 1990;i:1233-5.

6 Jones D, Lessells A, Eldridge J. Campylobacter-like organisms on the gastric mucosa: culture, histological and serological studies. $f$ Clin Pathol 1984;37:1002-6.

7 Goodwin C, Blincow E, Warren J, Sanderson C, Easton L. Evaluation of cultural techniques for isolating Campylobacter pyloridis from endoscopic biopsies of gastric mucosa. F Clin Pathol 1985;38:1127-31.

8 Hazell S, Borody T, Lee A. Campylobacter pyloridis gastritis: detection of urease as a marker of bacterial gastritis: detection of urease as a marker of bacterial
colonisation and gastritis. Am $\mathcal{f}$ Gastroenterol 1987; 82:292-6.

9 Evans DJ, Evans DG, Graham DY, Klein PD. A sensitive and specific serologic test for detection of Campylobacter pylori infection. Gastroenterology 1989;96:1004-8.

10 Sobala GM, Crabtree JE, Pentith JA, et al. Screening dyspepsia by serology to Helicobacter pylori. Lancet 1991;ii:94-6. 11 Ching CK. Screening for Helicobacter pylori in dyspepsia.
Lancet $1991 ; \mathrm{ii}: 394$.
12 Westblom TU, Madan E, Czinn S, Gudipati S, Midkiff BR. Sensitivity and specificity of Pyloriset, a latex agglutination test for detection of Helicobacter pylori infection. Gastroenterology 1991;100:A184

13 Taha AS, Boothman P, Holland P, et al. Gastric mucosal prostaglandin synthesis in the presence of Campylobacter pylori in patients with gastric ulcers and non-ulcer dyspepsia. Am $\mathcal{f}$ Gastroenterol 1990;85:47-50.

14 Whitehead R, Truelove SC, Bear MWL. The histological diagnosis of chronic gastritis in fibreoptic gastroscope biopsy specimens. $f$ Clin Pathol 1972;25:1-11.

15 Dixon MF, O'Connor HJ, Axon ATR, King RFJG, Johnston D. Reflux gastritis: distinct histopathological entity. 7 Clin Pathol 1986;39:524-30.

16 Dixon MF, Wyatt J Burk DA, Rathbone BJ. Lymphocytic gastritis-relationship to Campylobacter pylori infection. f Pathol 1988;154:125-32.

17 Taha AS, Nakshabendi I, Lee FD, Sturrock RD, Russell RI Chemical gastritis and Helicobacter pylori related gastritis in patients receiving non-steroidal anti inflammator drugs-comparison and correlation with peptic ulceration. 7 Clin Pathol 1992;45:135-9.

$18 \mathrm{McNemar} \mathrm{Q}$. Note on the sampling error of the difference between correlated proportions or percentages. Psychometrika 1947;12:152-7.

19 Morris A, Ali MR, Brown P, Lane M, Patton K. Campylobacter pylori infection in biopsy specimens of gastric antrum; laboratory diagnosis and estimation of sampling error. $\mathcal{J}$ Clin Pathol 1989;42:727-32.

20 Meyer B, Werth B, Beglinger C, et al. Helicobacter pylori infection in healthy people: a dynamic process? Gut 1991;32:347,-50.

21 Vaira D, Migioli M, Holton J, et al. Prevalence of IgG, IgA, IgM to Helicobacter pylori in 1018 blood donors. Gut 1991;32:A564.

22 Caruso I, Bianchi Porro GB. Gastroscopic evaluation of anti-inflammatory agents. $\mathrm{Br} \mathrm{Med} \mathcal{F}$ 1980;280:75-8.

23 Farah D, Sturrock RD, Russell RI. Peptic ulceration in rheumatoid arthritis. An Rheum Dis 1988;47:478-80.

24 Skander MP, Ryan FB. Non-steroidal anti inflammatory drugs and pain free peptic ulceration in the elderly. $\mathrm{Br}$ drugs and pain free pepti
Med $f$ 1988;297:883-4.

25 Martin DF, Montgomery E, Dobek AS, Patrissi GA, Peura DA. Campylobacter pylori, NSAIDs, and smoking: risk factors for peptic ulcer disease. Am $\mathcal{f}$ Gastroenterol 1989;84:1268-72.

26 Caselli M, Pazzi P, La Corte R, Aleotti A, Trevisani L, Stabellini G. Campylobacter-like organisms, non-steroidal anti inflammatory drugs and gastric lesions in patients with rheumatoid arthritis. Digestion 1989;44: $101-4$.

27 Laine L, Marin-Sorenson M, Weinstein MW. Helicobacter pylori (HP) prevalence and mucosal injury in gastric ulcers (GUs): relationship to chronic non-steroidal anti ulcers (GUs): relationship to chronic non-steroidal anti 1991;100:A103.

28 Jones STM, Clague RB, Eldridge J, Jones DM. Serological evidence of infection with Helicobacter pylori may predict gastrointestinal intolerance to non-steroidal anti inflammatory drug (NSAID) treatment in rheumatoid arthritis. Br F Rheumatol 1991;30:16-20.

29 Feldman M, Colturic TJ. Effect of indomethacin on gastric acid and bicarbonate secretion in humans. Gastroenterology 1984;87:1339-43.

30 Gerkens JF, Shand DG, Flexner C, Nies A, Oates J, Data J. Effect of indomethacin and aspirin on gastric blood flow and acid secretion. $f$ Pharmacol Exp Ther 1977; 203:646-52.

31 Levine RA, Schwartzel EH. Effect of indomethacin on basal and histamine stimulated human gastric acid secretion. and histamine stimulate

32 Menguy $R$, Masters YF. Effect of aspirin on gastric mucus secretion. Surg Gynaecol Obstet 1985;120:92-8.

33 Menguy $R$, Desbaillets L. Role of inhibition of gastric mucous secretion in the phenomenon of gastric mucosal injury by indomethacin. Am $₹$ Dig Dis 1967;12:862-6. 34 Veenedaal RA, Pena AS, Meijer JL, et al. Longterm pylori infection. Gut 1991;32:1291-4. 